\title{
Liver Mitochondrial Respiratory Function and Coenzyme $Q$ Content in Rats on a Hypercholesterolemic Diet Treated With Atorvastatin
}

\author{
O. ULIČNÁ ${ }^{1}$, O. VANČOVÁ ${ }^{1}$, I. WACZULÍKOVÁ ${ }^{2}$, P. BOŽEK ${ }^{3}$, L. ŠIKUROVÁ ${ }^{2}$, \\ V. BADA ${ }^{1}$, J. KUCHARSKÁ ${ }^{1}$
}

${ }^{1}$ Pharmacobiochemical Laboratory of Third Department of Internal Medicine, Faculty of Medicine, Comenius University, Bratislava, Slovak Republic, ${ }^{2}$ Department of Nuclear Physics and Biophysics, Faculty of Mathematics, Physics and Informatics, Comenius University, Bratislava, Slovak Republic, ${ }^{3}$ Department of Clinical Biochemistry and Hematology Saint Michal Hospital, Bratislava, Slovak Republic

Received June 22, 2011

Accepted September 2, 2011

On-line January 31, 2012

\section{Summary}

Statins, inhibitors of 3-hydroxy-3-methylglutaryl coenzyme A (HMG-CoA) reductase, are effective drugs in the treatment of hypercholesterolemia, however, their undesirable actions are not fully known. We investigated the effects of atorvastatin on the oxidative phosphorylation and membrane fluidity in liver mitochondria, and also on the coenzyme Q (CoQ) content in the mitochondria, liver tissue, and plasma of rats on a standard (C) and hypercholesterolemic ( $\mathrm{HCh})$ diet. Atorvastatin was administered at either low $\left(10 \mathrm{mg} \cdot \mathrm{kg}^{-1}\right)$ or high dose $\left(80 \mathrm{mg} \cdot \mathrm{kg}^{-1}\right)$ for four weeks. The high dose of the drug decreased the concentrations of total cholesterol and triacylglycerols in the plasma and liver of rats on a $\mathrm{HCh}$ diet. Administration of atorvastatin was associated with decreased oxygen uptake (state 3), and oxidative phosphorylation rate in the mitochondria of both $\mathrm{C}$ and $\mathrm{HCh}$ rats. Further, the drug influenced mitochondrial membrane fluidity and dose-dependently reduced concentrations of oxidized and reduced forms of $\mathrm{CoQ}$ in the mitochondria. Our findings point to an association between in vivo administration of atorvastatin and impaired bioenergetics in the liver mitochondria of rats, regardless of diet, in conjunction with simultaneous depletion of oxidized and reduced CoQ forms from the mitochondria. This fact may play a significant role in the development of statin-induced hepatopathy.

\section{Key words}

Hypercholesterolemia - Atorvastatin - Liver mitochondria • Oxidative phosphorylation $\bullet$ Coenzyme Q

\section{Corresponding author}

O. Uličná, Faculty of Medicine, Comenius University in Bratislava, Špitálska 24, 81372 Bratislava, Slovak Republic. Fax: +421259357242. E-mail: olga.ulicna@fmed.uniba.sk

\section{Introduction}

Hypercholesterolemia is considered as an important risk factor for the development of atherosclerotic cardiovascular diseases (Rose et al. 1977, Martin et al. 1986). Statin drugs represent the main therapeutic class of lipid lowering agents. Statins are generally well tolerated, however, they can produce adverse effects including, among others, skeletal muscle associated and dose dependent injuries ranging from muscle pain to clinical manifestations of rhabdomyolysis, as well as liver damages. Statins competitively inhibit 3-hydroxy-3-methylglutaryl coenzyme A (HMG-CoA) reductase, and thus reduce hepatocellular cholesterol production by lowering the synthesis of mevalonate. Mevalonate is a precursor of cholesterol but also of a whole class of other important substances, such as ubiquinone, dolichols and other isoprenoids (Liao 2002). Ubiquinone is also known as coenzyme $\mathrm{Q}$ (CoQ). It belongs to a homologous series of compounds that share a common benzoquinone ring structure but differ in the length of the isoprenoid side chain. While $\mathrm{CoQ}_{9}$ is the major CoQ homologue in rats (Lönnrot et al. 1998, Bhagavan and Chopra 2006), in humans the side chain 
comprises 10 isoprenoid units $\left(\mathrm{CoQ}_{10}\right)$.

CoQ plays a fundamental role in cellular bioenergetics since it acts as a redox cofactor in the mitochondrial respiratory chain and its cyclic electronproton (Q-cycle) transport functioning is essential for the optimal production of ATP. In its reduced form (ubiquinol) it is a potent lipophilic antioxidant and, as such, it is capable of recycling and regenerating other antioxidants such as tocopherol and ascorbate (Ernster and Dallner 1995, Crane 2001) thus preventing lipoperoxidation and subsequent changes in mitochondrial membrane fluidity.

It is believed that mitochondrial dysfunction plays a key role in the etiology of myopathy, cardiomyopathy, and hepatopathy. The progressive (cumulative) impairment of mitochondrial function leading to hepatocellular dysfunction cannot be excluded. However, direct evidence for the effect of statins on mitochondrial bioenergetics with respect to the $\mathrm{CoQ}$ content is lacking. For ethical reasons such studies cannot be conducted on humans.

The undoubtedly beneficial role of statins in the prevention and inhibition of coronary heart disease has resulted in their frequent use in clinical practice. However, epidemiological data on the increasing incidence of chronic liver diseases (non-alcoholic fatty liver disease - NAFLD) which can be displayed as simple steatosis, non-alcoholic steatohepatitis (NASH), fibrosis and eventually progress to cirrhosis (Angulo 2002), bring about the need for investigating whether statins can cause or contribute to the onset of the abovementioned liver disorders. One of the frequently used statins in clinical practice is atorvastatin, a reversible competitive inhibitor of HMG-CoA-reductase, which decreases tChol in plasma and also very low density lipoproteins (VLDL), low density lipoproteins (LDL), apolipoprotein B and triacylglycerol levels (BakkerArkema et al. 1996, Gómez-Domínguez et al. 2006).

Statins reduce biosynthesis of CoQ which is a mobile electron carrier in the respiratory chain of mitochondria. Based on this we hypothesized that inhibition of CoQ biosynthesis by a statin would decrease CoQ content in the mitochondria and consequently affect the rates of respiration and oxidative phosphorylation. We designed an experiment on rats which were fed a hypercholesterolemic $(\mathrm{HCh})$ diet. Our aim was to assess CoQ content and mitochondrial respiratory function parameters in the livers of rats on a standard or $\mathrm{HCh}$ diet given atorvastatin at doses which were suspected to have some clinical effects. Since both $\mathrm{CoQ}$ and atorvastatin are lipophilic, and published evidence suggests that some of the membrane functions may be modulated by changes in membrane fluidity, we also hypothesized that atorvastatin treatment could affect the fluidity of mitochondrial membrane.

\section{Methods}

\section{Chemicals}

D(-) manitol, saccharose, potassium chloride, ethylenedinitrilotetraacetic acid disodium salt (Titriplex III), potassium dihydrogen phosphate, 2-[4-(2-hydroxyethyl)-1-piperazinyl]-ethansulfonate acid (HEPES), hexane, ethanol, methanol, acetonitrile, sodium dodecylsulphate (SDS) were obtained from Merck. Cholesterol, L (+) - glutamic acid monosodium salt monohydrate, adenosine 5'diphosphate sodium salt (ADP), L (-) malic acid sodium salt, dextran, butylhydroxytoluene (BHT) and coenzyme $\mathrm{Q}_{9}$ standard were obtained from Sigma. The remaining chemicals were of analytical grade purity and obtained from Centralchem.

\section{Animals}

Male Wistar rats $(210-270 \mathrm{~g})$ were obtained from Dobrá Voda (Slovakia). They were maintained in a $12 \mathrm{~h} \mathrm{light/dark}$ cycle at a constant temperature of $20-24{ }^{\circ} \mathrm{C}$ with free access to tap water and food. All experiments were carried out according to the guidelines for the care and use of experimental animals, and were approved by the State Veterinary Administration of the Slovak Republic.

\section{Experimental procedure}

The animals were randomly divided into six groups consisting of 10 rats. Three groups were on the standard diet (KKZ-P/M, Dobrá Voda) for eight weeks. The first group was an untreated control (C). The remaining two groups were treated with atorvastatin at a daily dose, either low $10 \mathrm{mg} \cdot \mathrm{kg}^{-1}$ (CA10) or high $80 \mathrm{mg} \cdot \mathrm{kg}^{-1}$ (CA80), for four weeks before the end of experiment. The next three groups were on a HCh diet (the standard diet enriched with $4 \%$ cholesterol and $10 \%$ saturated fat prepared as pellets) for eight weeks, untreated $(\mathrm{HCh})$ and treated as mentioned above (HChA10; HChA80). Atorvastatin was given to the animals using the gastric gavage technique. To ensure identical experimental conditions, $\mathrm{C}$ and $\mathrm{HCh}$ groups 
were administered with tap water via a gastric tube in the same manner as the experimental groups.

After eight weeks and 24 hours after the last administration of atorvastatin, the rats were anesthetized with thiopental at a dose of $100 \mathrm{mg} \cdot \mathrm{kg}^{-1}$. Blood samples were taken from the abdominal aorta into heparinized tubes. Plasma samples were frozen until analyses. The livers were removed and samples from the right lobe were cut off, weighed and stored at $-70{ }^{\circ} \mathrm{C}$ for determination of total cholesterol (tChol), triacylglycerols (TAG) and CoQ. The remaining liver tissue was immediately used for mitochondria isolation.

\section{Biochemical analysis}

Activities of alanine aminotransferase (ALT) and aspartate aminotransferase (AST) as well as concentrations of tChol and TAG in plasma were evaluated by standard automated techniques using the Hitachi Analyzer Model 911 and adequate kits from the Roche Company (Switzerland). Concentration of tChol in the liver tissue was determined according to Abell et al. (1952), and TAG according to Jover (1963). Samples of liver tissues for analysis were homogenized in a chloroform/methanol mixture (1:1) for tChol determination and in a chloroform/methanol mixture (2:1) for TAG determination. Oxidized and reduced forms of $\mathrm{CoQ}\left(\mathrm{CoQ}_{9-0 x}\right.$ and $\left.\mathrm{CoQ}_{9-\text { red }}\right)$ were determined by the HPLC method with spectrophotometric detection (Lang et al. 1986, Kucharská et al. 2007). The liver tissue was homogenized using Ultra-Turrax in water with an addition of BHT and SDS. Homogenate or mitochondrial suspension was extracted by a hexane/ethanol mixture $(5: 2)$. The organic phase was evaporated under nitrogen and the residue dissolved in ethanol before measurement.

\section{Isolation of mitochondria}

Mitochondria were isolated from freshly excised livers by differential centrifugation as described by Hogeboom (1955), with some modification. The isolation medium was prepared according to Sammut et al. (1998), with the following modification: $225 \mathrm{mmol} \cdot \mathrm{l}^{-1}$ mannitol, $75 \mathrm{mmol} \cdot \mathrm{l}^{-1}$ sucrose, and $0.2 \mathrm{mmol} \cdot \mathrm{l}^{-1}$ Titriplex III. Liver was minced in the isolation medium ( $\mathrm{pH} 7.4$ ) at $4{ }^{\circ} \mathrm{C}$, and homogenized using a teflon-to-glass homogenizer. The homogenate was centrifuged at $700 \mathrm{~g}$ for $10 \mathrm{~min}$., the supernatant was decanted and centrifuged at $5600 \mathrm{~g}$ for $10 \mathrm{~min}$. The mitochondrial pellet was washed twice with isolation medium. The resulting pellet was resuspended in the same medium to a final protein concentration of 20-40 mg. $\mathrm{ml}^{-1}$. All procedures were performed at $4{ }^{\circ} \mathrm{C}$. Proteins were determined according to Lowry et al. (1951).

\section{Measurement of mitochondrial function}

Respiratory function of the mitochondria was determined using the voltamperometric method on an oxygraph Gilson 5/6 H (USA) with a Clark oxygen electrode at $30{ }^{\circ} \mathrm{C}$. The incubation medium was prepared as described by Rouslin and Millard (1980) with a modification: $12.5 \mathrm{mmol} \cdot \mathrm{l}^{-1} \mathrm{HEPES}, 122 \mathrm{mmol} \cdot \mathrm{l}^{-1}$ $\mathrm{KCl}, 3 \mathrm{mmol} \cdot \mathrm{l}^{-1} \mathrm{KH}_{2} \mathrm{PO}_{4}, 0.5 \mathrm{mmol} \cdot \mathrm{l}^{-1}$ Titriplex III, and $2 \%$ dextrane. Glutamate/malate at $2.5 \mathrm{mmol} \cdot \mathrm{l}^{-1}$ was used as a NAD substrate. For assessing stimulated oxygen consumption, $500 \mathrm{nmol}$ of ADP was added.

The following parameters of oxidative phosphorylation were determined in the liver mitochondria: the rate of oxygen uptake by the mitochondria stimulated with ADP - state $3\left[\mathrm{QO}_{2}\left(\mathrm{~S}_{3}\right)\right]$ expresses the velocity of oxygen consumption by mitochondria in the presence of ADP and substrate. The rate of basal oxygen uptake by mitochondria without ADP - state $4\left[\mathrm{QO}_{2}\left(\mathrm{~S}_{4}\right)\right]$ denotes how fast oxygen is used by mitochondria in the presence of substrate only. Respiratory control ratio (RCR) - ratio of state 3 to state 4 indicates the dependence of respiration rate on availability of ADP. The higher the RCR value, the tighter is the coupling of oxidation to phosphorylation. The oxidative phosphorylation rate (OPR) determines the rate of ATP generation in state 3 (Estabrook 1967).

\section{Biophysical analysis}

Membrane fluidity was assessed as a fluorescence anisotropy of 1,6-diphenyl-1,3,5hexatriene (DPH). A high degree of fluorescence anisotropy indicates a high degree of structural order, which indicates lower fluidity. Briefly, isolated mitochondria were diluted to a level at which no significant light scattering had been recorded (30 $\mu \mathrm{g} / \mathrm{ml})$. Each sample was equilibrated with $0.25 \mu \mathrm{M}$ $\mathrm{DPH}$ at $22 \pm 0.7^{\circ} \mathrm{C}$ in the dark for $20 \mathrm{~min}$. Then the steady-state anisotropy was determined as the mean of ten consecutive recordings taken for every sample during the plateau phase. The mitochondria used in these experiments were intact, in a de-energized (nonrespiring) state and were maintained at $4{ }^{\circ} \mathrm{C}$ until measured. For details see Waczulíkova et al. (2010). 
Table 1. Body weight, liver weight and biochemical parameters in plasma and liver after atorvastatin treatment.

\begin{tabular}{|c|c|c|c|c|c|c|}
\hline & $\mathbf{C}$ & CA10 & CA80 & HCh & HChA10 & HChA80 \\
\hline Initial body weight [g] & $229 \pm 14.49$ & $230 \pm 10.54$ & $222.5 \pm 11.65$ & $236 \pm 15.06$ & $237.8 \pm 19.11$ & $236.5 \pm 17.65$ \\
\hline Final body weight [g] & $370.5 \pm 35.94$ & $363 \pm 27.41$ & $349.4 \pm 29.57$ & $401 \pm 59.53$ & $394.4 \pm 48.31$ & $377.5 \pm 35.99$ \\
\hline Liver weight $[g]$ & $12.21 \pm 1.46$ & $11.94 \pm 1.65$ & $11.76 \pm 1.87$ & $16.2 \pm 2.93 * *$ & $15.6 \pm 2.22$ & $13.9 \pm 1.31^{\#}$ \\
\hline \multicolumn{7}{|l|}{ Plasma } \\
\hline tChol $\left[\mathrm{mmol} . \mathrm{l}^{-1}\right]$ & $1.46 \pm 0.26$ & $1.19 \pm 0.15$ & $1.39 \pm 0.30$ & $3.15 \pm 0.47 * *$ & $2.95 \pm 0.57$ & $2.70 \pm 0.30^{\#}$ \\
\hline$T A G\left[\mathrm{mmol}^{-1} \mathrm{l}^{-1}\right]$ & $1.27 \pm 0.47$ & $0.95 \pm 0.22$ & $0.75 \pm 0.24^{*}$ & $1.59 \pm 0.56$ & $1.57 \pm 0.68$ & $1.43 \pm 0.61$ \\
\hline$A L T\left[\mu k a t . l^{-1}\right]$ & $0.95 \pm 0.19$ & $1.25 \pm 0.48$ & $1.06 \pm 0.15$ & $1.22 \pm 0.25^{*}$ & $1.13 \pm 0.28$ & $1.53 \pm 0.45^{+}$ \\
\hline$A S T\left[\mu k a t . l^{-1}\right]$ & $1.68 \pm 0.41$ & $1.84 \pm 0.54$ & $1.80 \pm 0.10$ & $1.92 \pm 0.53$ & $1.66 \pm 0.36$ & $1.74 \pm 0.25$ \\
\hline $\operatorname{Co} Q_{9-o x}$ & 0.155 & 0.165 & $0.068^{* *++}$ & 0.166 & 0.151 & $0.062^{\# \#+}$ \\
\hline$\left[\mu \mathrm{mol} . \mathrm{I}^{-1}\right]$ & $(0.134-0.188)$ & $(0.124-0.175)$ & $(0.049-0.086)$ & $(0.147-0.194)$ & $(0.120-0.174)$ & $(0.056-0.083)$ \\
\hline \multicolumn{7}{|l|}{ Liver } \\
\hline tChol & 5.45 & 5.52 & 6.22 & $119.33 * *$ & 100.82 & $36.29^{\# \#++}$ \\
\hline$\left[m m o l . \mathrm{kg}^{-1}\right]$ & $(5.14-5.74)$ & $(5.43-5.68)$ & $(5.56-6.49)$ & $(83.12-127.84)$ & $(76.19-113.52)$ & $(26.57-54.60)$ \\
\hline$T A G$ & 8.93 & 8.06 & 7.35 & $39.34 * *$ & 44.04 & $20.34^{\#++}$ \\
\hline$\left[\mathrm{mmol} . \mathrm{kg}^{-1}\right]$ & $(8.03-9.35)$ & $(7.07-8.66)$ & $(5.84-9.22)$ & $(33.46-47.73)$ & $(37.65-49.19)$ & $(17.24-23.97)$ \\
\hline $\operatorname{Co} Q_{9-o x}$ & 67.7 & 54.4 & 61.4 & $38.5 * *$ & $27.7^{\#}$ & $30.9^{\#}$ \\
\hline$\left[\right.$ nmol. $\left.g^{-1}\right]$ & $(59.6-73.7)$ & $(46.3-66.5)$ & $(55.5-62.8)$ & $(32.2-41.9)$ & $(24.0-31.9)$ & $(24.8-33.1)$ \\
\hline $\operatorname{Co} Q_{9-\text {-red }}$ & 57.3 & 54.5 & 49.6 & $21.5^{* *}$ & 21.4 & 25.4 \\
\hline$\left[\right.$ nmol.g $\left.g^{-1}\right]$ & $(54.1-75.6)$ & $(47.6-59.1)$ & $(46.1-66.3)$ & $(17.0-22.9)$ & $(16.5-21.7)$ & $(23.9-30.4)$ \\
\hline
\end{tabular}

Experimental groups: C - control, CA10 - control + atorvastatin $10 \mathrm{mg} \cdot \mathrm{kg}^{-1}$, CA80 - control + atorvastatin $80 \mathrm{mg} \cdot \mathrm{kg}^{-1}, \mathrm{HCh}-$ hypercholesterolemic, HChA10 - hypercholesterolemic + atorvastatin $10 \mathrm{mg} \cdot \mathrm{kg}^{-1}$, HChA80 - hypercholesterolemic + atorvastatin $80 \mathrm{mg} \cdot \mathrm{kg}^{-1}$. Data are expressed as mean \pm S.D. (standard deviation) for the normally distributed variables; otherwise median (M) and lower quartile $Q_{1}$-upper quartile $Q_{3}, M\left(Q_{1}-Q_{3}\right)$, are used. Sample means of normally distributed variables were compared with one-way analysis of variance. If the overall test statistic was significant, multiple comparisons were performed with the Tukey-Kramer test. For non-normal variables, significance of differences was tested by means of the Kruskal-Wallis test. Post hoc pairwise comparisons were performed with the Connover-Inman test. Indices: * $\mathrm{p}<0.05, * * \mathrm{p}<0.005$ vs. $\mathrm{C}, \# \mathrm{p}<0.05, \# \# \mathrm{p}<0.005$ vs. HCh, $+\mathrm{p}<0.05$, $++\mathrm{p}<0.005$ vs. either CA10 or HChA10.

\section{Statistical analysis}

Data were checked for normality with the Shapiro-Wilk W-test. Normally distributed variables are described as mean \pm S.D. (standard deviation); otherwise median $(\mathrm{M})$ and quartile ranges from the lower quartile $\mathrm{Q}_{1}$ to the upper quartile $\mathrm{Q}_{3}\left(\mathrm{Q}_{1}-\mathrm{Q}_{3}\right)$, are used (Table 1). Oneway analysis of variance, followed either with the Dunnett test for multiple comparisons with the control or TukeyKramer test for all pairwise comparisons, was used. In the case of non-normality and/or unequal variances in between groups being compared, a non-parametric alternative (the Kruskal-Wallis test and the post hoc pairwise comparisons with the Connover-Inman test) was performed.

\section{Results}

At the end of the experiment, the mean body weight of $\mathrm{C}$ and $\mathrm{HCh}$ groups did not significantly differ.
Atorvastatin administration did not influence the weights of rats on a standard, or on a $\mathrm{HCh}$ diet. However, the average weight of the liver increased significantly in the group on the $\mathrm{HCh}$ diet in comparison with the control group on the standard diet. Liver weights of rats on the standard diet were not affected, but those of rats on the $\mathrm{HCh}$ diet and administered the higher dose of atorvastatin were decreased (HChA80; $<<0.05$; Table 1).

Animals on the $\mathrm{HCh}$ diet had an increased tChol concentration in their plasma $(p<0.005)$, which was reduced by the higher dose of atorvastatin (HChA80; $\mathrm{p}<0.05)$. The plasma concentrations of TAG were not affected by the HCh diet. In the group on the standard diet, TAG concentration in plasma decreased by the high dose of atorvastatin (CA80; $<<0.05)$. In the group on the $\mathrm{HCh}$ diet atorvastatin had no effect. ALT activity was increased in the HCh group $(p<0.05)$, whereas AST activity was unchanged in comparison with the control 

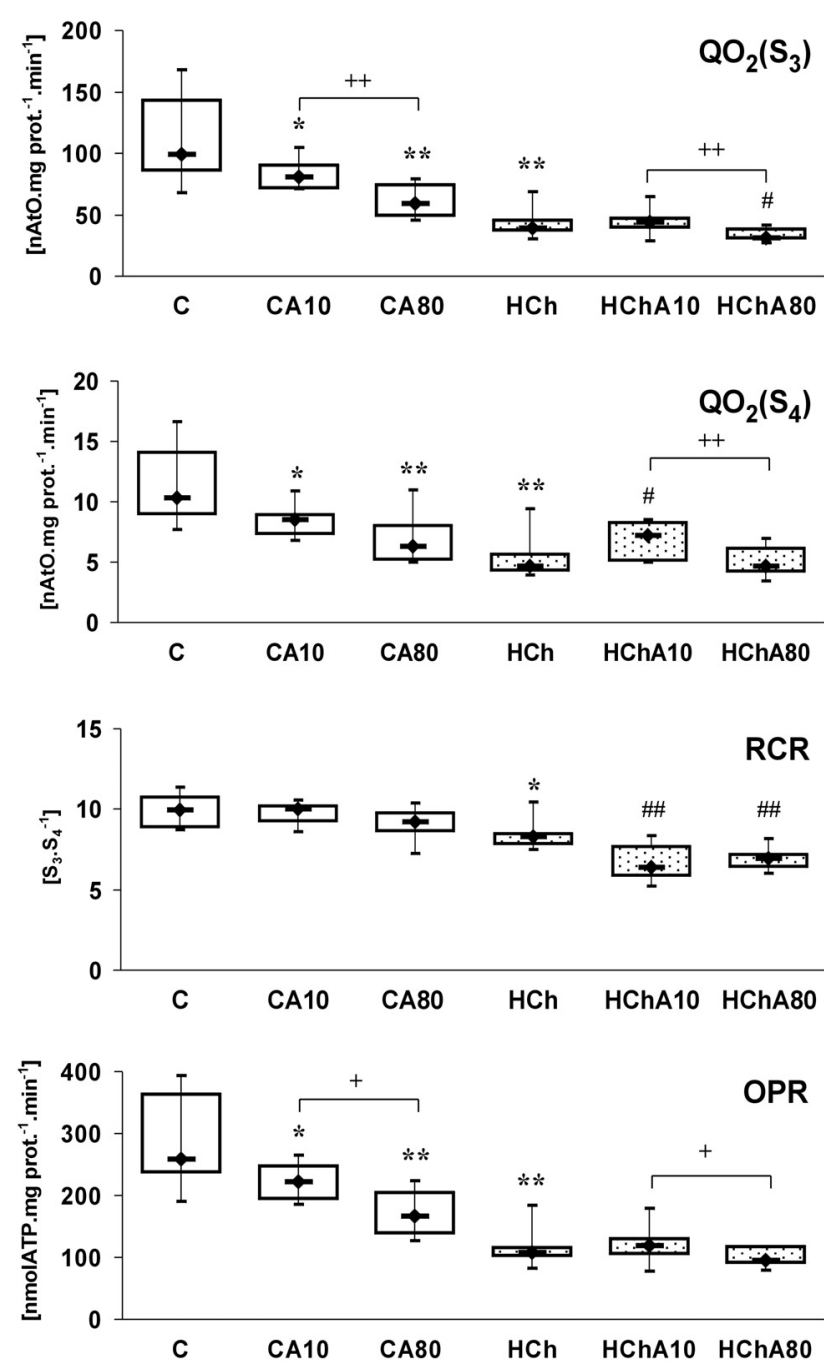

Fig. 1. Parameters of liver mitochondrial function following atorvastatin treatment. $\mathrm{QO}_{2}\left(\mathrm{~S}_{3}\right)$ - ADP stimulated respiration rate, $\mathrm{QO}_{2}\left(\mathrm{~S}_{4}\right)$ - basal respiration rate, $\mathrm{RCR}$ - respiratory control ratio, OPR - oxidative phosphorylation rate. Experimental groups: C - control, CA10 - control + atorvastatin $10 \mathrm{mg} \cdot \mathrm{kg}^{-1}$, CA80 control + atorvastatin $80 \mathrm{mg} \cdot \mathrm{kg}^{-1}, \mathrm{HCh}$ - hypercholesterolemic, HChA10 - hypercholesterolemic + atorvastatin $10 \mathrm{mg} \cdot \mathrm{kg}^{-1}$, HChA80 - hypercholesterolemic + atorvastatin $80 \mathrm{mg} \cdot \mathrm{kg}^{-1}$. Data are presented as median (horizontal bar with a diamond sign) and lower-upper quartile range and minimal and maximal value for rats on standard diet (open boxes) and on HCh diet (dotted boxes). Significance of differences was tested by means of the Kruskal-Wallis test. Post hoc pairwise comparisons were performed with the Connover-Inman test. Indices: $* \mathrm{p}<0.05$, $* * \mathrm{p}<0.005$ vs. $\mathrm{C}, \# \mathrm{p}<0.05$ vs. HCh, $+\mathrm{p}<0.05,++\mathrm{p}<0.005$ vs. either CA10 or HChA10.

group. Atorvastatin did not affect the activities of aminotransferases in the plasma. The plasma concentration of $\mathrm{CoQ}_{9-\mathrm{ox}}$ decreased following the higher dose of atorvastatin in both the group on standard diet (CA80; $\mathrm{p}<0.005)$, and the group on the $\mathrm{HCh}$ diet $($ HChA80; $\mathrm{p}<0.005)$ (Table 1).

There were significantly increased concentrations of tChol and TAG in the livers of the group of rats on the $\mathrm{HCh}$ diet $(\mathrm{p}<0.005)$ in comparison with the control group. Unlike the lower statin dose, the higher dose effectively reduced these elevated concentrations (HChA80; $<<0.005$; Table 1).

We found markedly decreased parameters of oxidative phosphorylation $(\mathrm{p}<0.005$ for oxygen consumption rate in state 3 , state 4 and OPR; $p<0.05$ for $\mathrm{RCR}$ ) in the liver mitochondria of $\mathrm{HCh}$ animals in comparison with control values (C). Oxygen consumption rate in state 3 was reduced in the $\mathrm{HCh}$ group on higher dose of atorvastatin (HChA80; $\mathrm{p}<0.05)$ and RCR was lowered by both doses of atorvastatin (HChA10, HChA80; $<$ 0.005) when compared with the $\mathrm{HCh}$ group. In the control animals oxygen consumption rates in state 3 , state 4 and OPR decreased upon administration of both, the lower (CA10; $\mathrm{p}<0.05)$ and the higher $(\mathrm{CA} 80 ; \mathrm{p}<0.005)$ doses of atorvastatin, whereas RCRs were not affected. Our findings at low and high atorvastatin doses indicate a dose-dependent impairment of mitochondrial function. The lowest rate of oxygen consumption in state 3 and ATP production was found in the $\mathrm{HCh}$ group given the higher dose of atorvastatin (Fig. 1).

The results concerning CoQ levels showed decreased concentrations of both oxidized and reduced $\mathrm{CoQ}_{9}$ in the liver mitochondria of rats on the $\mathrm{HCh}$ diet $(\mathrm{HCh} ; \mathrm{p}<0.05)$ in comparison with the control group. Administration of atorvastatin at both doses further deepened this trend (HChA10, HChA80; $<<0.005)$. In the groups on the standard diet atorvastatin decreased concentrations of both forms of CoQ (all $\mathrm{p}<0.05$ ). The most pronounced decrease in reduced $\mathrm{CoQ}_{9}$ was in HChA80 ( $<<0.005)$ (Fig. 2). In the liver tissue, the levels of $\mathrm{CoQ}_{9-\mathrm{ox}}$ and $\mathrm{CoQ}_{9 \mathrm{red}}$ were lowered by the $\mathrm{HCh}$ diet $(\mathrm{p}<0.005)$ in comparison with the control group. The $\mathrm{CoQ}_{9-0 x}$ level was further reduced by atorvastatin treatment (HChA10, HChA80; $<<0.05$; Table 1).

The steady-state fluorescence anisotropy of DPH was used to study the effect of atorvastatin on the physical state of mitochondrial membrane lipids. As expected, membrane fluidity (inversely related to anisotropy) decreased in the animals on $\mathrm{HCh}$ diet $(\mathrm{p}<0.05)$. The diet-induced increase in the lipid order was completely prevented in the rats on higher dose of atorvastatin ( $<<0.005$; Fig. 3$)$ thus approaching values found in the controls. The increase in lipid order in the control groups cannot be considered conclusive $(\mathrm{p}=0.11$ and 0.18 for lower and higher doses, respectively). 

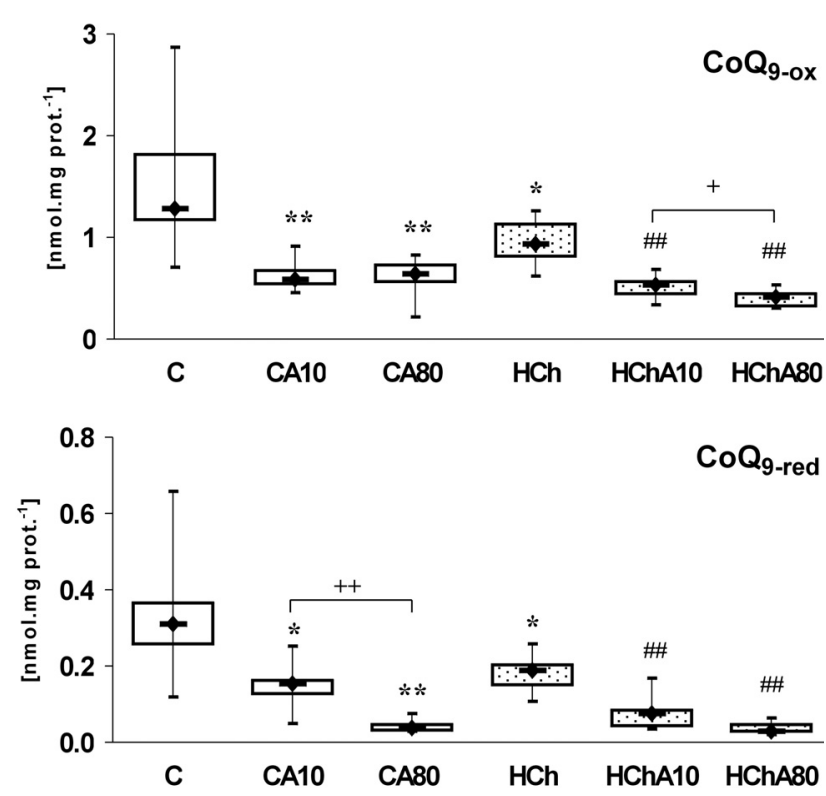

Fig. 2. Concentrations of oxidized and reduced coenzyme $\mathrm{Q}_{9}$ $\left(\mathrm{CoQ}_{9}\right)$ in liver mitochondria after atorvastatin treatment. Experimental groups: $\mathrm{C}$ - control, CA10 - control + atorvastatin $10 \mathrm{mg} \cdot \mathrm{kg}^{-1}$, CA80 - control + atorvastatin $80 \mathrm{mg} \cdot \mathrm{kg}^{-1}, \mathrm{HCh}-$ hypercholesterolemic, HChA10 - hypercholesterolemic + atorvastatin $10 \mathrm{mg}^{\mathrm{kg}} \mathrm{g}^{-1} \mathrm{HChA80}$ - hypercholesterolemic + atorvastatin $80 \mathrm{mg}^{-1} \mathrm{gg}^{-1}$. Data are presented as median (horizontal bar with a diamond sign) and lower-upper quartile range and minimal and maximal value for rats on standard diet (open boxes) and on HCh diet (dotted boxes). Significance of differences was tested by means of the Kruskal-Wallis test. Post hoc pairwise comparisons were performed with the ConnoverInman test. Indices: $* p<0.05, * * p<0.005$ vs. $C, \# \# p<0.005$ vs. $\mathrm{HCh},+p<0.05,++p<0.005$ vs. either CA10 or HChA10.

\section{Discussion}

Overconsumption of highly calorific foods, in particular a high-fat diet, is important in the development of hyperlipidemia, non-alcoholic fatty liver disease (NAFLD) and non-alcoholic steatohepatitis (NASH). An increase in tChol and TAG in the plasma, together with the onset and development of steatosis after the administration of a $\mathrm{HCh}$ diet, has been evidenced in several animal studies (Matos et al. 2005, Kováŕ et al. 2009, Kučera et al. 2010). We also showed that the HCh diet significantly increased tChol concentration in plasma and liver tissue. In addition, it reduced membrane lipid fluidity in the liver mitochondria. Plasma TAG concentration increased only slightly, but their accumulation in the liver induced a fatty liver. We found increased ALT activity in rats on the HCh diet, whereas AST activity was not affected. In the groups on the standard diet or for those on the HCh diet, atorvastatin did not affect the activities of aminotransferases. This suggests that the administration of atorvastatin did not

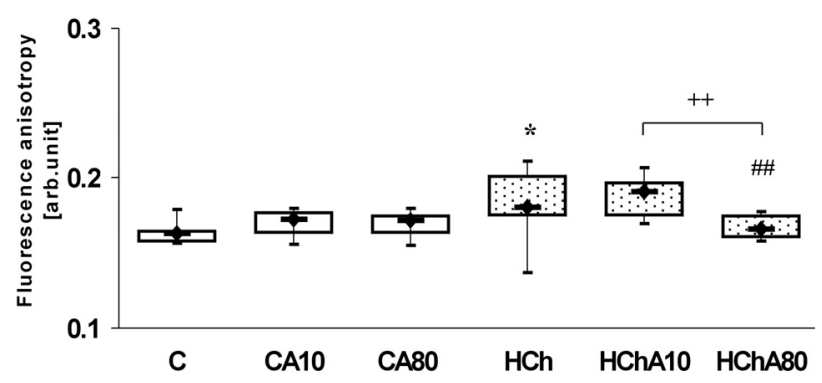

Fig. 3. Mitochondrial membrane fluidity expressed as a reciprocal of fluorescence anisotropy of DPH following atorvastatin treatment. Experimental groups: C - control, CA10 - control + atorvastatin $10 \mathrm{mg}^{\mathrm{kg}}{ }^{-1}, \mathrm{CA} 80$ - control + atorvastatin $80 \mathrm{mg} \cdot \mathrm{kg}^{-1}$, $\mathrm{HCh}$ - hypercholesterolemic, HChA10 - hypercholesterolemic + atorvastatin $10 \mathrm{mg} \cdot \mathrm{kg}^{-1}, \mathrm{HChA} 80$ - hypercholesterolemic + atorvastatin $80 \mathrm{mg}^{-1} \mathrm{~kg}^{-1}$. Data are presented as median (horizontal bar with diamond sign) and lower-upper quartile range and minimal and maximal value for rats on standard diet (open boxes) and on HCh diet (dotted boxes). Significance of differences was tested by means of the Kruskal-Wallis test. Post hoc pairwise comparisons were performed with the ConnoverInman test. Indices: $* \mathrm{p}<0.05$ vs. $\mathrm{C}, \# \# \mathrm{p}<0.005$ vs. $\mathrm{HCh}$, $++p<0.005$ vs. either CA10 or HChA10.

impair the membranes of hepatocytes. However, the drug significantly influenced membrane fluidity in the liver mitochondria of rats on the $\mathrm{HCh}$ diet. It has long been known that exogenously induced changes in the molar ratio of cholesterol/phospholipid of cell membranes induced by a change in cholesterol content may affect a number of membrane properties. Further, lipophilic compounds, such as atorvastatin, are able to interact with membranes in a transient manner, which itself may change membrane dynamics. Although the extent to which atorvastatin alters mitochondrial function in vivo is not yet understood, it is anticipated to alter both $\mathrm{CoQ}$ levels (and thus antioxidant defence) and membrane lipid composition, which might depress oxygen consumption and energy production in the mitochondria. Our study was not aimed at investigating whether, and to which extent the diet- or drug-induced alterations in mitochondrial cholesterol/phospholipid ratio (and concomitantly in mitochondrial membrane fluidity) could be directly responsible for the impairment of mitochondrial function. However, we attribute the observed alterations in mitochondrial bioenergetics to the drug-induced decrease in the concentration of $\mathrm{CoQ}$, since fast lateral diffusion of small lipophilic quinones is assumed to be fluidity-independent (Lenaz 1987). To summarize the above: administration of the high dose of atorvastatin resulted in a reduction of $\mathrm{tChol}$ in the plasma and liver of rats on the $\mathrm{HCh}$ diet, and significantly reduced the degree of steatosis and diet-induced membrane rigidity in liver mitochondria. 
These findings are consistent with clinical studies showing that atorvastatin is beneficial in patients with NASH and NAFLD (Gómez-Domínguez et al. 2006, Kimura et al. 2010). Atorvastatin effectively improves NAFLD hyperlipidemia and inhibits liver steatosis in rats on a high-fat diet (Ji et al. 2011).

Statins have been known to reduce circulating CoQ in animal models (Willis et al. 1990) and humans (Folkers et al. 1990, Rundek et al. 2004). In our study, we found a decreased concentration of CoQ in the plasma following the higher dose of atorvastatin in the animals given a standard or $\mathrm{HCh}$ diet. Reduction of CoQ may be considered as a significant adverse effect of statin therapy. Moreover, unsatisfactory synthesis of CoQ may reduce plasma and liver antioxidant capacity and negatively influence the membranes as they are the primary targets of reactive oxygen species. Oxidation can affect lipid fluidity, permeability and consequently the function of the membrane. Thus, since the majority of CoQ in hepatocytes is present in membrane systems including mitochondrial ones (Bentinger et al. 2003), and since CoQ is an integral part of the so-called Q-cycle in the electron transport chain, any decrease in the endogenous synthesis of CoQ will lead to a decreased capacity of the respiratory chain. Moreover, modifications of membrane structure and dynamics change the working environment for mitochondrial enzymes and redox carrier molecules, which might also contribute to impaired mitochondrial bioenergetics.

Fat accumulation is associated with ultrastructural abnormalities of liver mitochondria. Electron microscope images have revealed that mitochondria in NAFLD are large and swollen, scarce in number, and the matrix is hypodense with paracrystalline inclusions. These mitochondrial changes were found in a mouse model with a fatty acid oxidation defect and hepatic steatosis (Wei et al. 2008). Hepatic mitochondrial abnormalities in patients (Caldwell et al. 1999) and rats (Rector et al. 2010), with hepatic steatosis and reduced mitochondrial oxidative capacity in the livers of diabetic rats on HCh diet (Uličná and Volkovová 1996) were found.

This was also confirmed by our results on the respiratory function of mitochondria isolated from livers of rats on a $\mathrm{HCh}$ diet. These mitochondria showed a reduced rate of oxygen consumption, phosphorylation rate and RCR in comparison with the group on a standard diet. Atorvastatin significantly reduced oxidative phosphorylation parameters in the rats on a standard diet.
In the $\mathrm{HCh}$ groups, treatment with atorvastatin at both doses was associated with a decrease in RCR, which indicates a lowered coupling of the oxidation to phosphorylation. Oxygen consumption rate in state 3 was decreased only at the higher dose of atorvastatin. However, it should be stressed that the lowest values of the monitored parameters were found in the mitochondria isolated from livers of animals on the HCh diet following the higher dose of atorvastatin where, in fact, the extent of steatosis was vastly reduced. Concentrations of oxidized and reduced forms of CoQ were lowered in the liver mitochondria of rats on the standard as well as the $\mathrm{HCh}$ diet following atorvastatin treatment. We assume that the decreased capacity of the respiratory chain may be a consequence of a reduced synthesis of CoQ. Tavintharan et al. (2007) found that simvastatin at higher concentrations decreased mitochondrial $\mathrm{CoQ}_{10}$ levels, reduced ATP synthesis and increased DNA oxidative damage and the rate of HepG2 cell death. Treatment of the HepG2 cell line with simvastatin at a dose up to $10 \mu \mathrm{mol} / 1$ reduces HMG-CoA reductase activity in a dose-dependent manner. The authors concluded that simvastatin does not significantly affect the permeability of the mitochondrial inner membrane to ions, however, it does reduce ATP content. Since $\mathrm{CoQ}_{10}$ supplementation protected the hepatic cells line they suggest that its deficiency plays an important role in statin-induced hepatopathy. At the present time we cannot unambiguously assign our findings as direct contributors to the observed loss of efficiency in the electron transport chain. Conceivably, observed changes in CoQ levels and mitochondrial membrane lipid fluidity and function are interrelated in a complex manner.

In conclusion, we found a decreased $\mathrm{CoQ}_{9}$ content and reduced capacity of the respiratory chain and rate of ATP synthesis in the liver mitochondria after administration of atorvastatin in vivo. We were unable to find research dealing with the in vivo effects of atorvastatin on mitochondrial function in rat liver. We revealed an association between decreased CoQ in the plasma, depletion of mitochondrial CoQ and, at the same time, decreased respiratory function of the liver mitochondria of rats given standard and $\mathrm{HCh}$ diets with atorvastatin. We attribute the observed alterations in mitochondrial bioenergetics to the reduced CoQ concentration, since it appears unlikely that ubiquinone diffusion can be the rate-limiting step in electron transfer. A dose-dependent effect of atorvastatin on mitochondrial CoQ depletion and compromised bioenergetic function 
might play an important role in statin-induced hepatopathy. Our results contribute to existing views concerning adverse effects of statins on the liver, mainly those associated with the use of higher doses.

\section{Conflict of Interest}

There is no conflict of interest.

\section{Acknowledgements}

The technical assistance of Ludmila Butašová and Anna Štetková is gratefully appreciated. We would like to thank Richard Veal for language corrections. The study was supported by the Slovak Grant Agency for Science: VEGA No. 1/0328/10 and partially by a scientific grant MH SR 2007/29-UK-06.

\section{References}

ABELL LL, LEVEY BD, BRODIE BB, KENDALL FE: A simplified method for the estimation of total cholesterol in serum and demonstration of its specificity. J Biol Chem 195: 357-366, 1952.

ANGULO P: Nonalcoholic fatty liver disease. N Engl J Med 346: 1221-1231, 2002.

BAKKER-ARKEMA RG, DAVIDSON MH, GOLDSTEIN RJ, DAVIGNON J, ISAACSOHN JL, WEISS SR, KEILSON LM, BROWN WV, MILLER VT, SHURZINSKE LJ, BLACK DM: Efficacy and safety of a new HMG-CoA reductase inhibitor, atorvastatin, in patients with hypertriglyceridemia. JAMA 275: 128-133, 1996.

BENTINGER M, DALLNER G, CHOJNACKI T, SWIEZEWSKA E: Distribution and breakdown of labelled CoQ ${ }_{10}$ in rat. Free Rad Biol Med 34: 563-575, 2003.

BHAGAVAN HN, CHOPRA RK: Coenzyme Q10: Absorption, tissue uptake, metabolism and pharmacokinetics. Free Rad Res 40: 445-453, 2006.

CALDWELL SH, SWERDLOW RH, KHAN EM, IEZZONI JC, HESPENHEIDE EE, PARKS JK, PARKER WD: Mitochondrial abnormalities in non-alcoholic steatohepatitis. J Hepatol 31: 430-434, 1999.

CRANE FL: Biochemical functions of coenzyme Q10. J Am Coll Nutr 20: 591-598, 2001.

ERNSTER L, DALLNER G: Biochemical, physiological and medical aspects of ubiquinone function. Biochim Biophys Acta 1271: 195-204, 1995.

ESTABROOK RW: Mitochondrial respiratory control and the polarographic measurement of the ADP : O ratios. In: Methods in Enzymology. Oxidation and Phosphorylation. RW ESTABROOK, ME PULLMAN (eds), Academic Press Inc., New York, 1967, pp 41-47.

FOLKERS K, LANGSJOEN P, WILLIS R, RICHARDSON P, XIA LJ, YE CHQ, TAMAGAWA H: Lovastatin decreases coenzyme Q levels in humans. Proc Natl Acad Sci USA 87: 8931-8934, 1990.

GÓMEZ-DOMÍNGUEZ E, GISBERT JP, MORENO-MONTEAGUDO JA, GARCÍA-BUEY L, MORENO-OTERO R: A pilot study of atorvastatin treatment in dyslipemid non-alcoholic fatty liver patients. Aliment Pharmacol Ther 23: 1643-1647, 2006.

HOGEBOOM GH: Fractionation of cell components of animal tissues. In: Methods in Enzymology. SP COLOWICK, NO KAPLAN (eds), Academic Press Inc., New York, 1955, pp 17-19.

JI G, ZHAO X, LENG L, LIU P, JIANG Z: Comparison of dietary control and atorvastatin on high fat diet induced hepatic steatosis and hyperlipidemia in rats. Lipids Health Dis 10: 23-33, 2011.

JOVER A: Technique for the determination of serum glycerides. J Lipid Res 4: 228-230, 1963.

KIMURA Y, HYOGO H, YAMAGISHI S, TAKEUCHI M, ISCHITOBI T, NABESHIMA Y, ARIHIRO K, CHAYAMA K: Atorvastatin decreases serum levels of advanced glycation endproducts (AGEs) in nonalcoholic steatohepatitis (NASH) patients with dyslipidemia: clinical usefulness of AGEs as biomarker for the attenuation of NASH. J Gastroenterol 45: 750-757, 2010.

KOVÁŘ J, TONAR Z, HECZKOVÁ M, POLEDNE R: Prague hereditary hypercholesterolemic (PHHC) rat - a model of polygenic hypercholesterolemia. Physiol Res 58 (Suppl 2): S95-S99, 2009.

KUČERA O, GARNOL T, LOTKOVÁ H, STAŇKOVÁ P, MAZUROVÁ Y, HROCH M, BOLEHOVSKÁ R, ROUŠAR T, ČERVINKOVÁ Z: The effect of rat strain, diet composition and feeding period on the development of a nutritional model of nonalcoholic fatty liver disease in rats. Physiol Res 60: 317-328, 2011. 
KUCHARSKÁ J, GVOZDJÁKOVÁ A, ŠIMKO F: Simvastatin decreased coenzyme Q in the left ventricle and skeletal muscle but not in the brain and liver in L-NAME-induced hypertension. Physiol Res 56 (Suppl 2): S49-S54, 2007.

LANG JK, GOHIL K, PACKER L: Simultaneous determination of tocopherols, ubiquinols, and ubiquinones in blood, plasma, tissue homogenates, and subcellular fractions. Anal Biochem 157: 106-116, 1986.

LENAZ G: Lipid fluidity and membrane protein dynamics. Biosci Rep 7: 823-837, 1987.

LIAO JK: Isoprenoids as mediators of the biological effects of statins. J Clin Invest 110: 285-288, 2002.

LÖNNROT K, HOLM P, LAGERSTEDT A, HUHTALA H, ALHO H: The effects of lifelong ubiquinone Q10 supplementation on the Q9 and Q10 tissue concentrations and life span of male rats and mice. Biochem Mol Biol Intern 44: 727-737, 1998.

LOWRY OH, ROSENBROUGH UJ, FARR AL, RANDALL RJ: Protein measurement with the folin phenol reagent. J Biol Chem 193: 265-275, 1951.

MARTIN MJ, HULLEY SB, BROWNER WS, KULLER LH, WENTWORTH D: Serum cholesterol, blood pressure and mortality: implication from a cohort of 361662 man. Lancet 2: 933-936, 1986.

MATOS SL, PAULA H, PEDROSA ML, SANTOS RC, OLIVIERA EL, CHIANCA DA, SILVA ME: Dietary models for inducing hypercholesterolemia in rats. Brazil Arch Biol Technol 48: 203-209, 2005.

RECTOR RS, THYFAULT JP, UPTERGROVE GM, MORRIS EM, NAPLES SP, BORENGASSER SJ, MIKUS CR, LAYE MJ, LAUGHLIN MH, BOOTH FW, IBDAH JA: Mitochondrial dysfunction precedes insulin resistance and hepatic steatosis and contributes to the natural history of non-alcoholic fatty liver disease in an obese rodent model. J Hepatol 52: 727-736, 2010.

ROSE G, REID DD, HEMILTON PJ, KEEN H, JARRET RJ: Myocardial ischaemia risk factors and death from coronary heart disease. Lancet 1: 105-109, 1977.

ROUSLIN W, MILLARD RW: Canine myocardial ischemia: Defect in mitochondrial electron transfer complex I. J Mol Cell Cardiol 12: 639-645, 1980.

RUNDEK T, NAINI A, SACCO R, COATES K, DIMAURO S: Atorvastatin decreases the coenzyme $\mathrm{Q}_{10}$ level in the blood of patients at risk for cardiovascular disease and stroke. Arch Neurol 61: 889-892, 2004.

SAMMUT IA, THORNILEY MS, SIMPKIN S, FULLER BJ, BATES TE, GREEN CJ: Impairment of hepatic mitochondrial respiratory function following storage and orthotopic transplantation of rat livers. Cryobiology 36: 49-60, 1998.

TAVINTHARAN S, ONG CN, JEYASEELAN K, SIVAKUMAR M, LIM SC, SUM CF: Reduced mitochondrial coenzyme Q10 levels in HepG2 cells treated with high dose simvastatin: A possible role in statin-induced hepatotoxicity? Toxicol Appl Pharmacol 223: 173-179, 2007.

ULIČNÁ O, VOLKOVOVÁ K: Bioenergetics of liver mitochondria in rats on high lipid diet and chronic IDDM. Physiol Res 45: P32, 1996.

WACZULÍKOVÁ I, CAGALINEC M, ULIČNÁ O, SLEZÁK P, ZIEGELHÖFFER A: Biophysical investigation on left ventricular myocytes in rats with experimentally induced diabetes. Physiol Res 59 (Suppl 1): S9-S17, 2010.

WEI Y, RECTOR RS, THYFAULT JP, IBDAH JA: Nonalcoholic fatty liver disease and mitochondrial dysfunction. World J Gastroenterol 14: 193-199, 2008.

WILLIS RA, FOLKERS K, TUCKER JL, YE CQ, XIA LJ, TAMAGAWA H: Lovastatin decreases coenzyme Q level in rats. Proc Natl Acad Sci USA 87: 8928-8930, 1990. 